\title{
The Study of the Relationship Between the Quality of Work Life and the Organizational Commitment of the Employees of the Municipality of Zarandieh, Iran
}

\author{
Bita Parsa* \\ Assistant Professor of The Department of Management of The Institute of Higher Education Naser Khosrow. \\ Fatemeh Mirgloye Bayat \\ Graduated Master of Business Administration of Higher Education Institution Nasser Khosrow \\ Majid Fatehpour \\ Instructor of The Department of Management of The Institute of Higher Education Naser Khosrow
}

\begin{abstract}
The research has not sponsor. This article is the result of the M.Sc. thesis of Hakim Nasser Khosrow Saveh Higher Education Institution. The researchers expressed their gratitude and appreciation to the participants and principal of the municipality of Zarandieh, Iran for their cooperation to conducting this research.
\end{abstract}

\section{Abstract}

The present study aimed to determine the relationship between the quality of work life and organizational commitment of the employees of the municipality of Zarandieh, Iran. This research was a survey. Simple random sampling method was used to select 112 employees. A questionnaire including personal information, quality of work life, and organizational commitment was used to collect data. Data were analyzed by SPSS software version 20. The results showed that there was a significant correlation between organization commitment with health and safety $(\mathrm{r}=0.24)$, economic and family $(\mathrm{r}=0.28)$, social $(\mathrm{r}=0.44)$, self-esteem $(\mathrm{r}=0.40)$, cognitive and knowledge $(\mathrm{r}=0.50)$, and aesthetic needs $(\mathrm{r}=0.26)$. In general, there are positive and significant relationship between all components of quality of work life with organizational commitment $(\mathrm{p}<0.05)$.

Keywords: Quality of work life, Organizational commitment, Municipality, Employee

DOI: $10.7176 /$ JAAS/58-03

Publication date:September $30^{\text {th }} 2019$

\section{Introduction}

Human resources are considered as the most strategic resource and the most valuable asset in any organization (Nehrir, Ebadi, Sh, AA, \& Honarvar, 2010). Promised employees are recognized as a vital resource for the successful performance of organization. In fact, organizational success depends on employees and their commitment to a set of values, principles and beliefs. Committed and loyal employees, improve the position of the organization in society and provides the growth of an organization (Morrow, 2011). Organizational commitment is defined as the strong desire of a member to remain in the organization. Meyer and Allen define organizational commitment as a psychological state that links an individual to an organization, which expresses the desire, need or obligation to continue and serve in an organization. It reduces the probability of employees' voluntary exit from the organization (Meyer \& Allen, 1991) Organizational commitment includes three dimensions of emotional commitment, continuous commitment and normative commitment. Emotional commitment refers to emotional attachment of an individual to an organization that the person enjoys from replicating, affiliation, and membership in the organization. Continuous commitment means staying in the organization due to the costs of leaving. Normative Commitment is the desire to remain in the organization based on the ethical issue. Organizational commitment has positive consequences such as high job performance, productivity, job satisfaction, reduced absenteeism, organizational citizenship behaviour's, altruism and helping colleagues, and reducing job stress (Sajjad \& Abbasi, 2014). Low level of commitment has negative consequences such as abandonment, lack of desire to stay in the organization, reduction of work ethics, mental health disorder, low quality of work, lack of loyalty to the organization, illegal activity, disadvantage in the organization, reducing customer confidence and reducing the organization's earnings. In previous studies, negative relationship between organizational commitment and the desire to leave the job has been reported ( $\underline{H} .-T$. Chang, Chi, \& Miao, 2007). As far as employees are more committed to their organization, the percentage of employee survival in the organization will increase. The operating costs, employee performance and efficiency will improve in a highly committed environment. When employees' needs are not met in the workplace, they are likely to experience a lot of stress, with negative consequences for the welfare and job performance. Quality of work life (QWL) considers the organizational environment in accordance with employees' needs (health and safety, economic and family, social, esteem, actualization, knowledge and aesthetic). Studies show that 
implementation of the quality of work life program has reduced staff complaints, reduced absenteeism, increased employee perceptions and positive attitudes, increased employee participation and job satisfaction (Emadzadeh, Khorasani, \& Nematizadeh, 2012). On the other hand, QWL helps to meet the needs of employees for the improvement and long-term performance of the organization (Moseley, 2017). Gupta and Sharma say quality of work life is important for organizational performance, increasing employees' motivation and organizational commitment (Gupta \& Sharma, 2011) .

The goal of the quality of work life is to achieve effective strategies for promoting individual and organizational productivity. By increasing the quality of work life, employees will probably become more committed to their organization. Therefore, the aim of this study was to investigate the relationship between quality of work life and organizational commitment of the employees of the municipality state of Zarandieh, Iran.

\section{Material and Methods}

This research is a cross-sectional study. The statistical population of this research consisted of 159 employees of the municipality of Zarandieh, Iran in year 2018. Using Cochran's formula, 112 people were considered as sample size. The sampling method was a stratified-proportional survey that samples were collected from employees of various departments of the municipality of Zarandiyeh. The data collection tool was a structured questionnaire, including the demographic characteristics, quality of work life and organization commitment questionnaires. Quality of work life questionnaire developed by Sergi et al. 2001(Sirgy, Efraty, Siegel, \& Lee, 2001). This questionnaire was translated to Persian language by Parsa et al. in 2014 (Parsa, Idris, Samah, Wahat, \& Parsa, 2014). The reliability of this scale is confirmed by alpha Cronbach equal to 0.81 and its validity was estimated by content analysis. Reliability of the QWL in this study using Cronbach's alpha was 0.78 .

This QWL questionnaire consisted of 26 items including : health and safety needs with items (questions 13 ), economic and family needs with 4 items (questions 5 to 8), social needs with 4 items (questions 9 to 12) ), social support needs with 3 items (questions 13 to 15), self-esteem needs with 2 items (questions 16 to 17), talent development needs with 3 items (questions 18 to 20), cognitive and knowledge needs with 3 items (questions 21 to 23), the aesthetic needs with 3 items (questions 24-26).

The grades were scored on a 5-point Likert scale, Scores ranged from 1 (strongly disagree) to 5 (strongly agree).

Allan \& Meyer organizational commitment questionnaire was used to assess organizational commitment (Allen \& Meyer, 1990). The questionnaire consisted of 24 terms that were designed in three dimensions: affective commitment, continuous commitment, and normative commitment. Respondents were asked to determine the extent to which each of the questions reflects their organization in the aspects of quality of work life and organization commitment ( $1=$ almost never; $5=$ almost always). Validity and reliability of this questionnaire have been confirmed by Ravaghi et al. (2013) with Cronbach's alpha equal to 0.85 in Iran (Ravaghi, Shams, Aryan, \& Salehi, 2013). Then the collected data were analyzed by SPSS software version 21. Pearson correlation and linear regression tests were used to test the hypotheses of the research.

\section{Results}

Data in Table 1, reveals the descriptive analysis of quality of work life dimensions and organization commitment in this study.

Table 1: Descriptive characteristics of QWL dimensions and organization commitment (n=112)

\begin{tabular}{|l|l|l|l|l|l|}
\hline Variables & Mean & SD & Skewness & Kurtiosis & Min-max \\
\hline Health and Safety & 13.98 & 2.70 & -0.68 & 0.98 & $6-20$ \\
\hline Economic and family & 14.02 & 3.00 & 0.25 & -0.01 & $7-21$ \\
\hline Social & 14.97 & 3.08 & -0.55 & 0.43 & $6-21$ \\
\hline self-esteem & 16.20 & 3.39 & -0.08 & 0.45 & $6-21$ \\
\hline Talent & 15.84 & 3.30 & 0.01 & -0.73 & $8-22$ \\
\hline Cognitive \& knowledge & 16.70 & 6.48 & 0.98 & 0.39 & $1-4$ \\
\hline Aesthetic & 14.41 & 3.10 & 0.28 & -0.01 & $7-21$ \\
\hline Total QWL & 149.63 & 17.49 & -0.30 & 2.26 & $127-197$ \\
\hline Organization Commitment & 118.21 & 14.66 & -2.14 & 2.82 & $61-160$ \\
\hline
\end{tabular}


Table 2. Correlation between quality of life and organization commitment

\begin{tabular}{|l|l|l|}
\hline Variables & r & p \\
\hline Total QWL & 0.37 & $<0.001$ \\
\hline Health and Safety & 0.24 & $<0.001$ \\
\hline Economic and family & 0.28 & $<0.001$ \\
\hline Social & 0.44 & $<0.001$ \\
\hline Self-esteem & 0.40 & $<0.001$ \\
\hline Talent & 0.21 & $<0.01$ \\
\hline Cognitive \& knowledge & 0.50 & $<0.01$ \\
\hline Aesthetic & 0.26 & $<0.001$ \\
\hline
\end{tabular}

According to Table 2, it can be stated that the correlation between the total quality of work life and organizational commitment is 0.37 , which indicates a moderate and direct relationship between these variables. The correlation coefficient between employees' health and safety and organizational commitment is equal to 0.24 , which shows a positive and significant correlation between these variables $(\mathrm{p}<0.05)$. Correlation between the economic and family criteria and the organizational commitment is equal to 0.28 which indicates a moderate and direct relationship $(\mathrm{p}<0.05)$.

Correlation coefficient between social metrics and organizational commitment is 0.44 which shows a medium and direct relationship $(\mathrm{p}<0.05)$. Correlation coefficient between self-esteem and organizational commitment is equal to 0.40 , which shows a medium and direct relationship $(\mathrm{p}<0.05)$. The correlation coefficient between two talent flourishing and organizational commitment is equal to 0.21 , which indicates a direct and significant relationship. $(\mathrm{P}<0.05)$. The correlation coefficient between cognitive and knowledge criteria and organizational commitment is equal to 0.50 , which indicates a direct and medium relationship ( $p$ $<0.05)$. The correlation coefficient between the aesthetic criteria of the employees and organizational commitment is 0.26 which indicates a low and direct relationship $(\mathrm{p}<0.05)$.

Table 3. Regression analysis of QWL on organization commitment

\begin{tabular}{|l|l|l|l|}
\hline Variables & R & R square & Adjusted R square \\
\hline Total QWL & 0.37 & 0.13 & 0.13 \\
\hline Health and Safety & 0.24 & 0.05 & 0.05 \\
\hline Economic and family & 0.28 & 0.08 & 0.07 \\
\hline Social & 0.44 & 0.19 & 0.19 \\
\hline Self-esteem & 0.40 & 0.55 & 0.55 \\
\hline Talent & 0.21 & 0.04 & 0.03 \\
\hline Cognitive \& knowledge & 0.50 & 0.25 & 0.25 \\
\hline
\end{tabular}

DV: organization commitment

The results of multivariable regression analysis are shown in Table 3 . The value of $\mathrm{R}$ is the multiple correlation coefficient, which shows the severity of the relationship between the two independent and dependent variables and its value is always between 0 and 1 . In this study $R$ is equal to 0.37 , which indicates an average relationship between quality of work life and organizational commitment. The value of the coefficient of determination ( $\mathrm{R}$ square) was 0.13 and expresses the fact that about $13 \%$ of variations in the depended variable ( organization commitment) is related to the independent variable ( quality of work life).

The value of $\mathrm{R}$ equal to 0.24 , indicating an average relationship between the health and safety and organizational commitment. About $5 \%$ of variation in DV is explained by IV of health and safety of employees. The value of $\mathrm{R}$ equal to 0.44 , indicating a moderate relationship between the economic and family criteria with organization commitment of the employees. Approximately $8 \%$ of the variations of the DV is explained by this IV.

The $\mathrm{R}$ between self-esteem and organizational commitment is 0.40 , which indicates an average relation between employee self-esteem and organizational commitment. The value of the coefficient of determination 0.55 expresses the fact that about $55 \%$ of the variations in the organization commitment is explained by selfesteem of the employees.

The value $\mathrm{R}$ between the employee's talent flourishing and organizational commitment is 0.21 , which indicates a low relationship between the employee's talent flourishing and organizational commitment. Approximately $25 \%$ of the variations of the organizational commitment is explained by social needs of employees.

The value $\mathrm{R}$ between aesthetic criteria and organizational commitment is equal of 0.26 which indicates the medium relationship between the two variables. About $8 \%$ of variance on organizational commitment is explained by the aesthetic criteria of employees. 
Table 4.Ppredictive analysis of effects of QWL dimensions on organization commitment

\begin{tabular}{|l|l|l|l|l|}
\hline Variables & B standard & Error & t & p \\
\hline Total QWL & 0.44 & 0.05 & 4.55 & $<0.01$ \\
\hline Health and Safety & 1.50 & 0.53 & 2.84 & $<0.05$ \\
\hline Economic and family & 1.83 & 0.54 & 3.36 & $<0.01$ \\
\hline Social & 0.41 & 0.05 & 12.76 & $<0.001$ \\
\hline Self-esteem & 0.75 & 0.05 & 16.84 & $<0.001$ \\
\hline Talent & 1.08 & 0.44 & 2.44 & 0.016 \\
\hline Cognitive \& knowledge & 0.52 & 0.44 & 2.15 & 0.03 \\
\hline
\end{tabular}

DV: Organization commitment

Since the level of significance for all dimensions of quality of life variables is less than 0.05 , these variables are included in the Multiple Linear Regression Model. The results of Table 4 show that predictive effects of variables on organization commitment. According to this finding the highest effect of dimensions of QWL on the organization commitment related to the aesthetic criteria (1.87) followed by, economic and family (1.83), health and safety (1.50), talent(1.08), self-esteem (0.746), cognitive and knowledgeable $(0.520)$, Social $(0.41)$.

\section{Discussion}

According to the results, there was a relationship between the health and safety needs of the employees with their organizational commitment. One of the main tasks of human resource management is to increase the organizational commitment. To achieve organizational commitment, it is essential that employees have a high level of satisfaction to create value for the organization. One of the main causes of job satisfaction is job security and one of the pillars of job security is the safety and health of the workplace. When employees see their health and safety in organizations is a priorities and value in the organization, organizational commitment will increase and they are being interested to stay in the organization. The results of this hypothesis are consistent with other studies (Bakker, Schaufeli, Leiter, \& Taris, 2008; Grawitch, Gottschalk, \& Munz, 2006; Hosseini, Naderian, Homaye, \& Mosavi, 2008)

According to the results a strong and direct relationship was found between the economic and family needs with the organizational commitment. It should be said that with the increase of family and economic criteria, the organizational commitment of employees also increases. Fair and adequate payment is associated with positive attitude, personal and well-being and organization commitment. One of the main component of organizational commitment of employees is fair payment. Also, family aspects is important in quality of work life. According to previous research in Iran conducted by Hosseini et al., family issues have a direct and positive relationship with organizational commitment (Hosseini et al., 2008). Therefore, it should be noted that by observing economic and family needs, organizational commitment can be increased. Other studies showed a relationship between employee's' fair payment and organizational commitment (Bazaz Jazayeri \& Pardakhtchi, 2007; Reyasi, 2013). It also found that fair payments in the organization had the most impact on organizational commitment in comparison with other aspects of the quality of work life (Reyasi, 2013). In this way, if employees understand that their salaries and benefits are fair for their work, they are more likely to commit to the organization.

Results indicate a strong and direct relationship between the social status and organizational commitment. The social status deal with participation, democracy, social activities, and so on. The results indicate that the quality of democracy in the organization directly affects organizational commitment and organizational success. This results are in consistent with the findings of other studies (Feather \& Rauter, 2004; Fuller, Barnett, Hester, \& Relyea, 2003)

Self-esteem can be considered as important component of mental health. Results indicate that there is a strong relationship between self-esteem needs of the employees and organizational commitment. Self-esteem is also effective in many issues relating to the success and adaptability of a person. Self-esteem of an individual in his workplace forms according to his interests, talents, attitudes and cognition. It plays a constructive role in the loyalty of the individual to the organization and is one of the most important determinants of performance. On the other hand, organizational commitment is a kind of attitude and person's perception of the organization that influences its performance, loyalty and judgments. The results are consistent with Gagne and Deci (Gagné \& Deci, 2005) Bagtasus (Bagtasos, 2011) and Bani et al. (2004)(Banai, Reisel, \& Probst, 2004).

The results show a relationship between the talent prosperity and the organizational commitment. The results are similar with the results of Change (S.-C. Chang \& Lee, 2007) and Hosseini (Hosseini et al., 2008). The flourishing of talent in workplace means providing the ground for improving individual abilities, opportunities for development, opportunities for employing acquired skills and securing income. The talent prosperity leads to the employee's attachment to the organization, and his lifespan in the organization will increase. So, organizations that consider employees' commitment to fulfil their organizational goals, need to provide condition to promote talent prosperity of their staffs. 
Organizations must improve talent development and open the door for the value that these talents can offer. As a result, the efficiency of the staffs will be increase in the organization and their commitment to the organization will increases.

The results reveals relationship between the cognitive and knowledge needs of employees with organizational commitment. It should be noted that the cognitive and knowledge needs refer to the enjoyment of skills, information and new technologies at the work. These criteria make work faster, increase employee efficiency and resulted a greater organizational commitment. Staff training, increase skills of staffs and also makes people feel that they are good for the organization, and they tend to be more likely to stay in the organization. Increasing organizational commitment will strengthen the relationship between employees and the organization and will ensure organization success. The results of this study are consistent with the results of Gagnon (Gagnon, Jansen, \& Michael, 2008), Hosseini (Hosseini et al., 2008) and Hochwarter (Hochwarter, Witt, Treadway, \& Ferris, 2006) studies.

The finding show a relationship between the aesthetic needs of the employees with organizational commitment. The aesthetic refers to suitable working environment in terms of size, physical conditions, safety services, existence of friendly relationships at the workplace, and the existence of trust between individuals. According to the results of this research, these factors have led to an increase in organizational commitment. In fact, the aesthetic has a positive effect on the employees' morale, and increases employee performance and sense of accomplishment. The results are consistent with the findings of Rubel (2014), which indicate a direct and significant relationship between the secure working environment and organizational commitment (Rubel \& Kee, $\underline{2014})$.

\section{Conclusion}

In order to promote organization commitment, organizations need to pay more attention to employee safety and health programs, create a healthy atmosphere at work, create balance between work and non-working life , provide psychological security for their employees, pparticipate the employees in decision making, creating organizational justice and the climate of democracy to meet social standards that will increase the organizational commitment of the staff. In addition, provide opportunities for continuing education, and encourage employees to continue their education, in order to enhance knowledge about work activities.

In this research, there are some limitations that must be taken into account when considering the results. The possibility of unrealistic responses due to unwillingness to respond, lack of sufficient time or fear of disclosure to work. Participants from a particular stratum makes some difficulties to generalize outcomes to other organizations.

\section{Acknowledgments}

This article is the result of the M.Sc. thesis of Hakim Nasser Khosrow Saveh Higher Education Institution. The researchers expressed their gratitude and appreciation to the participants and principal of the municipality of Zarandieh, Iran for their cooperation to conducting this research.

\section{References}

Allen, N. J., \& Meyer, J. P. (1990). The measurement and antecedents of affective, continuance and normative commitment to the organization. Journal of occupational psychology, 63(1), 1-18.

Bagtasos, M. R. (2011). Quality of Work Life: A Review of Literature. DLSU Business \& Economics Review, 20(2).

Bakker, A. B., Schaufeli, W. B., Leiter, M. P., \& Taris, T. W. (2008). Work engagement: An emerging concept in occupational health psychology. Work \& Stress, 22(3), 187-200.

Banai, M., Reisel, W. D., \& Probst, T. M. (2004). A managerial and personal control model: Predictions of work alienation and organizational commitment in Hungary. Journal of International Management, 10(3), 375392.

Bazaz Jazayeri, A., \& Pardakhtchi, M. (2007). Creating model of assessing quality of life of staffs in organization. Management Science Journal, 5, 123-151.

Chang, H.-T., Chi, N.-W., \& Miao, M.-C. (2007). Testing the relationship between three-component organizational/occupational commitment and organizational/occupational turnover intention using a nonrecursive model. Journal of Vocational Behavior, 70(2), 352-368.

Chang, S.-C., \& Lee, M.-S. (2007). A study on relationship among leadership, organizational culture, the operation of learning organization and employees' job satisfaction. The learning organization, 14(2), 155185.

Emadzadeh, M. K., Khorasani, M., \& Nematizadeh, F. (2012). Assessing the quality of work life of primary school teachers in Isfahan City. Interdisciplinary Journal of Contemporary Research in Business, 3(9), 438448. 
Feather, N. T., \& Rauter, K. A. (2004). Organizational citizenship behaviours in relation to job status, job insecurity, organizational commitment and identification, job satisfaction and work values. Journal of occupational and organizational psychology, 77(1), 81-94.

Fuller, J. B., Barnett, T., Hester, K., \& Relyea, C. (2003). A social identity perspective on the relationship between perceived organizational support and organizational commitment. The Journal of Social Psychology, 143(6), 789-791.

Gagné, M., \& Deci, E. L. (2005). Self-determination theory and work motivation. Journal of Organizational behavior, 26(4), 331-362.

Gagnon, M. A., Jansen, K. J., \& Michael, J. H. (2008). Employee alignment with strategic change: A study of strategy-supportive behavior among blue-collar employees. Journal of Managerial Issues, 425-443.

Grawitch, M. J., Gottschalk, M., \& Munz, D. C. (2006). The path to a healthy workplace: A critical review linking healthy workplace practices, employee well-being, and organizational improvements. Consulting Psychology Journal: Practice and Research, 58(3), 129.

Gupta, M., \& Sharma, P. (2011). Factor credentials boosting quality of work life of BSNL employees in Jammu region. Asia Pacific Journal of Research in Business Management, 2(1), 79-89.

Hochwarter, W. A., Witt, L. A., Treadway, D. C., \& Ferris, G. R. (2006). The interaction of social skill and organizational support on job performance. Journal of Applied Psychology, 91(2), 482.

Hosseini, S., Naderian, M., Homaye, R., \& Mosavi, Z. (2008). Relation between quality of work life and organizational management for staffs of sport office of Esfahan. Journal of Sport management, 2, 168-181.

Meyer, J. P., \& Allen, N. J. (1991). A three-component conceptualization of organizational commitment. Human resource management review, 1(1), 61-89.

Morrow, P. C. (2011). Managing organizational commitment: Insights from longitudinal research. Journal of Vocational Behavior, 79(1), 18-35.

Moseley, L. (2017). Organizational Health Framework Approach to Explore Mindfulness as a Mechanism to Improve Employee Well-Being and Organizational Productivity. Northcentral University.

Nehrir, B., Ebadi, A., Sh, T., AA, K. Z., \& Honarvar, H. (2010). Relationship of job satisfaction and organizational commitment in hospital nurses. Journal Mil Med, 12(1), 23-26 [Persian].

Parsa, B., Idris, K. B., Samah, B. B. A., Wahat, N. W. B. A., \& Parsa, P. (2014). Relationship between quality of work life and career advancement among Iranian academics. Procedia-Social and Behavioral Sciences, 152, 108-111.

Ravaghi, H., Shams, L., Aryan, K. A., \& Salehi, M. (2013). Person-organization fit and organizational commitment in university hospitals of Tehran university of medical sciences. Health Inf Manage, 10(2), 110 .

Reyasi, H. (2013). Work life quality of nurses working in educational hospitals affiliated to Birjand University of Medical Sciences, 2012. Modern Care Journal, 10(1), 84-90.

Rubel, M. R. B., \& Kee, D. M. H. (2014). Quality of work life and employee performance: Antecedent and outcome of job satisfaction in Partial Least Square (PLS). World Applied Sciences Journal, 31(4), 456-467.

Sajjad, N. K., \& Abbasi, B. (2014). Studying the Relationship between Quality of work life and Organizational Commitment. Research Journal of Recent Sciences, 2277, 2502.

Sirgy, M. J., Efraty, D., Siegel, P., \& Lee, D.-J. (2001). A new measure of quality of work life (QWL) based on need satisfaction and spillover theories. Social indicators research, 55(3), 241-302. 